\title{
The postnatal growth of the temporal bone and its implication for cochlear implantation in children
}

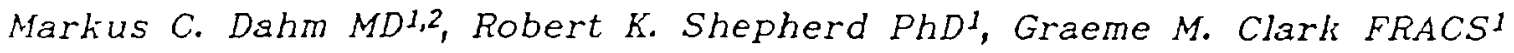

1 Department of Otolaryngology, University of Melbourne, Australia 2 HNO - Klinik, Medizinische Hochschule Hannover, Konstanty- Gutschow- Str. 8, 3000 Hannover 61, Germany

The growth of the human temporal bone is of practical concern if young children are implanted. It is feared that the normal development of the temporal bone after implantation may displace the electrode array and jeopardize the success of the device. To evaluate the extent of growth 60 cadaver specimens of all ages were examined by direct anatomical measurements. The bones were dissected by imitating the cochlear implantation surgical procedure in the temporal bone laboratory. 19 anatomical /surgical landmarks with implications for cochlear implant surgery were identified and the distance between them measured. The inner ear and middle ear are adult size at birth. The external auditory canal and most parts of the temporal bone are subject to significant lateral growth. The size of the pneumatised mastoid was found to increase in all directions. In the facial recess however, no postnatal growth could be noted. Between birth and adulthood a considerable amount of growth is to be expected between the sinodural angle and the round window, the landmarks representing the implantation site for the receiver/stimulator and the electrode entry site respectively. From an anatomical and surgical point of view, cochlear implantation in very young children proved to be feasible, provided the electrode array is secured close to the cochlea and the design accommodates for controlled leadwire lengthening.

The work was funded by the NIH- Contract N01-DC-7-2342. M.C. Dahm is supported by grant Da 232/1-2 from the Deutsche Forschungsgemeinschaft, Germany. 


\section{University Library}

\section{- M M N E R VA A gateway to Melbourne's research publications}

Minerva Access is the Institutional Repository of The University of Melbourne

\section{Author/s:}

Dahm, Markus C.;Shepherd, Robert K.;Clark, Graeme M.

Title:

The postnatal growth of the temporal bone and its implications for cochlear implantation in children

Date:

1993

\section{Citation:}

Dahm, M. C., Shepherd, R. K., \& Clark, G. M. (1993). The postnatal growth of the temporal bone and its implications for cochlear implantation in children. In Annual and General Scientific Meeting of the Australian Society of Otolarngology Head and Neck Surgery, Adelaide.

Persistent Link:

http://hdl.handle.net/11343/26889 